\title{
EDITORIAL
}

\section{Method of body conservation; Is it time to review?}

Formalin is a conventional chemical used for body preservation. It is the aqueous form of formaldehyde. Therefore, its use is not confined to cadaveric conservation but also as a powerful disinfectant. Formaldehyde is made out of methane. Forest fires, automobile exhaust and tobacco smoking releases methane which gets oxidized and combined with other carbonic compounds to get converted to formaldehyde. However, Formaldehyde is volatile especially when exposed to direct sunlight. Interestingly, formaldehyde is made within the human body in minute amounts by oxidizing amino acids. Further, formaldehyde has also being discovered in outer space. The property that helps formaldehyde to act as a tissue fixative and as an embalming agent is its nature to form cross bonds with amino acids.

Even though traditionally formalin was used to preserve bodies worldwide, now most of the countries have raised concerns or stopped using formalin due to its carcinogenic property. Embalming solutions containing formalin have formaldehyde emissions. These can easily enter the lungs via inhalation. It had been measured even a smaller quantity such as $0.1 \mathrm{ppm}$ can trigger, headaches, watery eyes, burning throat and difficulty in breathing. People who are exposed for a long time may develop nasopharyngeal carcinoma, leukemia. It would be very interesting if a prospective study could be done to see the effects on health by chronic exposure to formalin among people doing embalming, who manufacture goods using formalin, staff of Departments of Anatomy etc. in Sri Lanka.

Currently, there are multiple commercially prepared solutions for body preservation where a very low or no formalin is used. In 1978 Bradbury and Hoshino published their solution made up of Formaldehyde, Phenol and monoethyl glycol. This allowed some flexibility of the cadaver but individual organ preservation especially the brain was not satisfactory. Later Frolich et at(1984), Frewein et al.(1987), Ikeda et al. (1988) published similar solutions to Bradbury and Hoshino but they used Ethanol instead of Methanol andreplaced monoethyl glycol with glycerine and chloral hydrate with propylene glycol.

In 1992 and 2002 Thiel published a more environmental friendly solution containing water, formaldehyde, 4chloro-3-methylphenol, morpholine and propylene glycol. The cadavers had better colour preservation and allowed tissue and joint mobility, however, the muscle tissue was disintegrating and was expensive.

Barton et al. omitted formaldehyde and only used water, Ethanol, Phenol and Glycerine. Hammer et al. (2012) used ethanol, glycerin and thymol but there isn't adequate data on suitability for dissections. Shi et al.(2012) replaced formaldehyde by hydroxymethyl 
phosphonium chloride which has the additional fungicide properties. Literature suggest that this solution can keep the cadavers preserved for 2 years. However, the ability to do dissections is not clear. Further, studies are available using different preservation solutions but the suitability of such preserved bodies for dissections is unclear. Some of the identified problems were lack of a continuous supply, expensive and high tendency for fungal growth.

The "Cresando" mix is a formula by the Otago University, New Zealand. Here, the phenol is replaced by phenoxitol, hence, the cadavers have less odor. Nevertheless, we need more data to conclude whether it is the ideal body preserving solution for us.

Plastination is another novel method of body preservation where the body water and fat is replaced by silicone resins or epoxy polymers. This is an very advanced way method of body preserving bodies as the cadavers are odorless, more durable, can be touched but less flexible and make it not suitable for dissecting. However, plastination is a method that could be used to preserve dissected specimens for a long time allowing some amount of tissue mobility and it is very suitable to be used in prepairing museum specimens. The plastinized specimens could be just left in room temperature and the students could handle the specimens and learn anatomical structural relations. However, it is an expensive process and tissue dissection would not be possible after plastination, hence, making it more suitable for prosected specimens but unsuitable to carry out dissections.
In conclusion, I firmly believe that it is time for us to review the body preservation processes and minimize the formalin usage. Multiple body preservation methods could be adopted within the Departments of Anatomy to serve different purposes and thereby reduce the formalin usage. Body coolers using low temperatures could be used to store prosected specimens which are used for practical examinations. Measuring the amount of hazardous chemicals in our dissection halls when using the standard high formalin concentrated formula need to be done in a routine manner and pay more attention to improve the ventilation and maintain a free air flow across the dissecting halls. Let's initiate collaborative research and find the best preservation solution to fit our country considering the cost, availability of ingredients, temperature, storing facilities and the purpose and it may even require the usage of multiple methods of preservation to serve different purposes.

\section{References}

1. Bradbury SA, Hoshino K. An improved embalming procedure for long-lasting preservation of the cadaver for anatomical study. Acta Anat (Basel) 1978;101:97-103. [PubMed]

2. Frølich KW, Andersen LM, Knutsen A, et al. Phenoxyethanol as a nontoxic substitute for formaldehyde in long-term preservation of human anatomical specimens for dissection and demonstration purposes. Anat Rec. 1984;208:271-278. [PubMed] 
3. Frewein J, Steinmann W, Muller U. [Experiences with reduced formalin fixation of specimens and formalinfree preservation of anatomic samples] AnatHistolEmbryol. 1987;16:250-253. [PubMed]

4. Ikeda A, Ugawa A, Kazihara Y, et al. Arterial patterns in the hand based on a three-dimensional analysis of 220 cadaver hands. J Hand Surg. 1988; 13:501-509. [PubMed]

5. Thiel W. Die Konservierungganzer Leichen in natürlichenFarben. Ann Anat. 1992;174:185-195. [PubMed]

6. Thiel W. Ergänzungfür die KonservierungganzerLeichennach W. Thiel. Ann Anat. 2002;184:267269. [PubMed]
7. Barton DPJ, Davies DC, Mahadevan $\mathrm{V}$, et al. Dissection of soft-preserved cadavers in the training of gynaecological oncologists: report of the first UK workshop. Gynecol Oncol. 2009;113:352-356. [PubMed]

8. Hammer N, Loffler S, Feja C, et al. Ethanol-glycerin fixation with thymol conservation: a potential alternative to formaldehyde and phenol embalming. Anat Sci Educ. 2012;5:225-233. [PubMed]

9. Shi KQ, Shao SX, Yin WG. An improved non-formaldehyde tissue preservative. Adv Mat Res. 2012;356:360-363.

\section{Dr. Sithara Dissanayake,}

MBBS (Col), MD (Otorhinolaryngology), DOHNS (UK)

Senior Lecturer/ Consultant ENT Surgeon,

Department of Anatomy,

Faculty of Medical Sciences,

University of Sri Jayewardenepura,

Gangodawila,

Nugegoda. 